\title{
Disentangling the effects of empathy components on Internet gaming disorder: A study of vulnerable youth in China
}

\author{
BRYANT P. H. HUI ${ }^{1}$, ANISE M. S. WU² and NGAI PUN ${ }^{1}$ \\ ${ }^{1}$ Department of Sociology, Faculty of Social Sciences, University of Hong Kong, Hong Kong SAR, China \\ ${ }^{2}$ Department of Psychology, University of Macau, Macao SAR, China
}

(Received: August 15, 2018; revised manuscript received: January 16, 2019; accepted: March 9, 2019)

\begin{abstract}
Background and aims: Previous research shows that empathy can be one of the potential protective factors for Internet gaming disorder (IGD), yet the complex relationships between multidimensional factors of empathy and IGD remain understudied. Thus, a major question moving forward is to resolve the mixed empirical data by examining the specific contributions of empathy components. In this study, we disentangle the effects of cognitive component (i.e., perspective taking) and affective component (i.e., empathic concern and personal distress) on IGD symptoms and propose affect-oriented mediation pathways between them. Methods: We surveyed a large sample $(N=3,348)$ of Chinese vocational school students, one of the most vulnerable groups to online gaming addiction. Results: Our structural equation modeling results revealed that only personal distress, but not empathic concern or perspective taking, positively predicted IGD symptoms. However, empathic concern and personal distress were negatively and positively predicted gaming motive of escape from reality, respectively, which in turn predicted IGD symptoms. Furthermore, we found an indirect effect of perspective taking on IGD through empathic concern and then gaming motive of escape from reality. Discussion and conclusion: The findings underscore the importance of separating the affective and cognitive components to understand the complex relationships between the empathy and IGD, and support our theorizing of the affect-oriented mediation mechanism.
\end{abstract}

Keywords: empathy, escape from reality, gaming addiction, IGD, youth

\section{INTRODUCTION}

Gaming is becoming people's favorite online activity, especially in China. The number of online gamers in China has been mounting from 336 to 422 million in the past 5 years a $25 \%$ increase (China Internet Network Information Center [CINIC], 2018). Among those gamers, over 55\% are from high school, technical secondary school, technical school, and junior college (CINIC, 2016). Excessive and prolonged online gaming, however, may lead to various negative consequences, such as poor academic achievement (Rehbein, Kleimann, \& Mößle, 2010), low well-being and high loneliness (Lemmens, Valkenburg, \& Peter, 2011), and lack of real-life relationships (Allison, von Wahlde, Shockley, \& Gabbard, 2006). The fifth edition of Diagnostic and Statistical Manual for Mental Disorders (DSM-5; American Psychiatric Association [APA], 2013) has labeled Internet gaming disorder (IGD) as a potential behavioral addiction for further investigation. Proposed symptoms of IGD include preoccupation, withdrawal symptoms, tolerance, loss of control, loss of interest in non-gaming activities, conflicts, deception, mood modification, and various negative consequences. Such repetitive impairing behavioral pattern is often conceptualized under the umbrella term "problematic Internet use (PIU)" or "Internet addiction," which encompasses all potentially problematic Internet activities (e.g., gaming, social networking, and gambling; Fineberg et al., 2018). Recently, the World Health Organization (WHO) also recognized gaming disorder as a new mental health condition in the 11th edition of its International Classification of Diseases (WHO, 2018). It remains controversial if (Internet) gaming disorder should be considered as a mental disorder, but its inclusion as a mental disorder in the diagnostic classification systems is generally supported by both clinical evidence and public health needs (King et al., 2018; Rumpf et al., 2018). Extensive research from various fields has been conducted aiming to curb and alleviate the negative effects of Internet gaming (Kuss, 2013).

An emerging line of research examines the protective effect of empathy on Internet-related addictions. Yet, the empirical results are mixed (e.g., Collins \& Freeman, 2013; Gentile et al., 2011; Liau et al., 2015), and limited research has studied the mechanism of the relationship between empathy and IGD. Thus, a major question moving forward is to resolve the mixed empirical findings. We propose a

\footnotetext{
* Corresponding author: Dr. Bryant P. H. Hui; Research Assistant Professor; Department of Sociology, Faculty of Social Sciences, University of Hong Kong, 9/F, Jockey Club Tower, Pokfulam Road, Hong Kong SAR, China; Phone: +852 3917 2050; Fax: +852 2857 4074; E-mail: bryant09@hku.hk
}

This is an open-access article distributed under the terms of the Creative Commons Attribution-NonCommercial 4.0 International License, which permits unrestricted use, distribution, and reproduction in any medium for non-commercial purposes, provided the original author and source are credited, a link to the CC License is provided, and changes - if any - are indicated. 
possible solution by examining the unique contributions of cognitive and affective empathy components on IGD simultaneously. Deriving from self-regulation literature, we also explicate a new affect-oriented pathway from empathy to IGD. To test our proposal, we conducted a large study $(N=3,348)$ in nine Chinese vocational schools, which contain the largest proportion of vulnerable online gamers, and structural equation modeling (SEM) was employed to test our hypotheses.

\section{Empathy and its components}

Basically, empathy can be defined as "the reactions of one individual to the observed experiences of another" (Davis, 1983, p. 113). It consists of both cognitive and affective components (Davis, 1994). The cognitive component of empathy involves the cognitive ability to understand the other's feelings such as perspective taking, whereas affective component concerns the emotional responses to the emotional state of others, such as empathic concern and personal distress (Baron-Cohen \& Wheelwright, 2004).

Perspective taking - also cognitive role-taking or cognitive empathy - refers to the cognitive ability to understand the other's psychological point of view; it is based on a person's knowledge of the other's situation, character, values, and desires (Baron-Cohen \& Wheelwright, 2004; Davis, 1994). Empathic concern refers to "other-oriented emotion elicited by and congruent with the perceived welfare of a person in need" (Batson, 2018, p. 59), while personal distress - also sympathetic pain or empathic distress - concerns self-oriented feelings of personal anxiety and unease in tense interpersonal settings (Batson, 2018), for example, seeing how upset your friend is (Batson, Early, \& Salvarani, 1997). Although some research treats empathy, perspective taking, and personal distress as distinct concepts (e.g., Eisenberg \& Okun, 1996; Eisenberg, Wentzel, \& Harris, 1998), empathy has been regarded as a multidimensional construct in prior and this study (e.g., Christov-Moore et al., 2014; Davis, 1983) and shown to play an important role for effective social interactions (e.g., Busby \& Gardner, 2008; De Wied, Branje, \& Meeus, 2007).

\section{Empathy and IGD}

In general, a number of studies have found that individuals who suffered from PIU are less empathic (e.g., Jiao, Wang, Peng, \& Cui, 2017; Lachmann et al., 2018; Melchers, Li, Chen, Zhang, \& Montag, 2015; Wang, Ge, Zhang, Liu, \& Luo, 2014). Its protective effect may be attributed to the resultant better social competence and relations, which are negatively associated with PIU (Caplan, 2002; Engelberg \& Sjöberg, 2004; Whang, Lee, \& Chang, 2003). Despite the consistent empirical evidence on the negative relationship between empathy and PIU, the findings on empathy and IGD are not very uniform, but mixed in the existing studies. To the best of our knowledge, there are six published studies of IGD or problem gaming in relation to empathy. Two studies found a negative association between empathy and gaming addiction symptoms (Che et al., 2017; Zhang et al., 2016). In addition, Tejeiro, Gómez-Vallecillo, Pelegrina, Wallace, and Emberley (2012) clustered a Spanish adolescent sample and found that the problem players group (vs. the social players group) reported a significantly lower score on empathy. Similarly, Gentile et al. (2011) studied a sample of Singaporean youth and demonstrated that the starts group (becoming pathological gamers during the study) reported a significantly lower score of empathy in comparison with the never pathological group (remained as non-pathological gamers) in a two-year longitudinal study. In contrast, Liau et al. (2015) found that, after controlling for gender and initial level of pathological gaming, empathy was not one of the significant predictors to pathological gaming in a regression model. In a similar vein, a study comparing empathy levels among gaming players found no significant differences among problematic gaming players, non-problematic gaming players, and non-gaming players groups (Collins \& Freeman, 2013).

The inconsistent findings may be due to the use of different operational definitions, measurement tools, and components to assess individuals' empathy level. For example, Gentile et al. (2011) and Liau et al. (2015) and used the same data set in which two measures of empathy were used, and the former found no relationship between pathological gambling and empathy (assessed by a subfactor in Personal Strengths Inventory-II of Liau, Tan, Li, \& Khoo, 2012), whereas the latter showed a significant relationship between pathological gambling and empathy (measured by Children's Empathic Attitudes Questionnaire of Funk, Fox, Chan, \& Curtiss, 2008). Moreover, although empathy is a multidimensional construct, and thus the cognitive and affective components should be measured separately in theory, a single construct of empathy was always used in prior studies (e.g., Che et al., 2017; Collins \& Freeman, 2013; Zhang et al., 2016), resulting in limited research effort looking into correlations among the empathy components and IGD. It would be beneficial to examine the relative explanatory power of an empathy component on IGD after controlling for the other components in order to understand which and how empathy components may be involved in IGD development and remission. Hence, the primary goal of this study is to disentangle the empathy components to see which one/s contribute/s to the prediction of IGD.

\section{Self-regulation and the affective pathway to $I G D$}

In addition to the direct effects, a few previous studies attempt to demonstrate possible indirect effects of empathy on IGD via depression (Zhang et al., 2016) and perceived self-efficacy (Che et al., 2017), but they only used a single construct of empathy. On shedding light from selfregulation literature, the second purpose of this study is to propose a new affect-oriented pathway from empathy components to IGD.

Deficient self-regulation (i.e., a diminished conscious control over one's behavior) has been proposed to explain the development of Internet-related addictions (LaRose, Lin, \& Eastin, 2003), given that both preoccupation and loss of control over the online activity are salient symptoms of the disorders. Self-regulation is closely related to emotional and social competence (McKown, Gumbiner, Russo, \& Lipton, 2009), while empathy is an important aspect of emotional competence, specifically in social context, and hence is 
considerably relevant for the quality of social functioning (Eisenberg et al., 1998). There is also evidence showing empathy is positively related to effortful control (Eisenberg \& Okun, 1996; Rothbart, Ahadi, \& Hershey, 1994). Therefore, we reasoned that empathic individuals may be optimally regulated in general.

Comparing with cognitive empathy components, we reasoned that affective components may be more related to IGD. Negative moods are consistently associated with IGD (Cheng, Cheung, \& Wang, 2018), and mood modification is probably the most commonly reported IGD symptom (Wu, Chen, Tong, Yu, \& Lau, 2018). Specifically, higher levels of personal distress may be associated with poor or deficient self-regulation (Eisenberg \& Okun, 1996). Failure to attend to the thoughts and feelings of another may make individuals vulnerable to rumination of and getting overwhelmed by their own distress (Posner \& Rothbart, 2000). It may in turn hamper their self-regulation processes (e.g., selecting, monitoring, and evaluating game use as a coping strategy for their negative mood alleviation) and hence contribute to the onset and persistence of IGD. Such notion is supported by evidence showing that online gaming players are more socially anxious than non-players (Lo, Wang, \& Fang, 2005). Hence, we theorized that personal distress - the affective component of empathy - has a positive association with IGD symptoms (Hypothesis 1).

Personal distress is associated with egoistic motivation to alleviate one's own aversive state (Eisenberg, 2010). Among gamers, those with higher levels of personal distress may tend to be more motivated to escape from reality, as a way to make themselves feel better. Supporting this, emotion-focused coping, such as venting, distraction, and avoidance, was found to be related to lower empathy (Carlo et al., 2012). Distraction and escape are not only related to more time spent on online gaming (van Ingen \& Matzat, 2018), but also explained the largest variance of IGD after general motivation (Wu, Lai, Yu, Lau, \& Lei, 2017). The closest clue for understanding the mechanism behind why personal distress might predict IGD is from Király et al. (2015) who demonstrated that gaming motive of escape explained the positive effect of general psychiatric distress on problematic online gaming. Collectively, the above findings provide a basis for theorizing that the motive of escape from reality can act as a mediator for an affect-oriented pathway between personal distress and IGD. This mediation effect was tested in this study (Hypothesis 2).

Empathic concern, an affective component of empathy, has been demonstrated as a desirable indicator of social competence (e.g., Riggio \& Taylor, 2000) and antecedent of prosocial behaviors (see Eisenberg \& Miller, 1987). We therefore hypothesized its negative association with IGD symptoms (Hypothesis 3). Contrary to self-oriented feelings of personal distress, individuals with higher levels of otheroriented emotions, empathic concern, are believed to be less likely to experience the gaming motive of escape from reality. People predisposed to sympathy - similar to empathic concern in a sense of experiencing other-oriented concern - are believed to be well-regulated, prone to general emotional intensity, and predisposed to experience positive emotion (Eisenberg et al., 1998). Thus, people with high empathic concern are likely to regulate their emotion and behavior with positive and constructive strategies (e.g., prosocial behaviors; Berry et al., 2018), rather than avoidance and escape (e.g., gaming) if socially tense stressors are present. Thus, we hypothesized that the motive of escape from reality would mediate the affect-oriented pathway from empathic concern to IGD symptoms (Hypothesis 4).

The ability of cognitive perspective taking is essential for experiencing other-oriented emotion of empathic concern. Eisenberg et al. (1998) have proposed that perspective taking may engender sympathy, in which he or she experiences other-oriented concern. Empirically, studies reported a strong correlation of over .50 between perspective taking and empathic concern (e.g., Melchers et al., 2015). We therefore argued that cognitive perspective taking is an antecedent of empathic concern (Batson, 2018), which in turn predicts gaming motive of escape from reality and then IGD. It was hypothesized that the negative association between perspective taking and IGD symptoms would be mediated by empathic concern and escape from reality (Hypothesis 5).

\section{The present study}

In short, by surveying a large sample, this is the first study examining how empathy may mitigate IGD in China youth. We aimed to (a) simultaneously test the complex relationships between the cognitive and affective components of empathy and IGD, and (b) suggest the affect-oriented mediation mechanisms via gaming motive of escape from reality. The findings not only fill out the existing research gap but also provide practical insights for empathy intervention on IGD prevention among Chinese vocational school students.

\section{METHODS}

\section{Participants and procedure}

Participants were recruited from vocational schools in Mainland China. School principals and teachers from 22 schools attended a conference for vocational school educators in late 2017. Among the vocational schools, nine from Anhui, Gansu, Guizhou, Hubei, Inner Mongolia, and Zhejiang were interested in participating in this study (response rate $=41 \%$ ). A convenience sample of 7,998 potential student participants were invited by an online survey link to take part in the study. After signing an online informed consent, 4,849 participants completed our online selfadministered survey using their computers or mobile devices on a voluntary basis (response rate $=61 \%$ ). We embedded six bogus items (e.g., "For this question, please select 'strongly agree"') in our survey to identify careless responses (Maniaci \& Rogge, 2014; Meade \& Craig, 2012). We only included those who answered four or more bogus items correctly and completed our survey in not less than $15 \mathrm{~min}$; therefore, our final sample was 3,348 participants (1,589 females, $47.46 \% ; M_{\text {age }}=18.20, S D_{\text {age }}=2.05$, age range $=15-24$ years $)$. 


\section{Measures}

Empathy. The empathy component from the Prosocial Personality Battery (Penner, 2002), with a 5-point Likert response scale (ranging from $1=$ strongly disagree to $5=$ strongly agree), was used to measure three subfactors of empathy, namely perspective taking, empathic concern, and personal distress. The measure was translated and back-translated by separate Chinese-English bilinguals. It consists of 12 items: perspective taking ( 5 items, Cronbach's $\alpha=.80$, after removing two items with negative item-total correlations), empathic concern (4 items, Cronbach's $\alpha=.66$, after removing two items with negative item-total correlations), and personal distress (3 items, Cronbach's $\alpha=.63$, after removing one item with negative item-total correlations). Sample items include "I sometimes try to understand my friends better by imaging how things look from their perspective" (perspective taking), "When I see someone being taking advantage of, I feel kind of protective toward them" (empathic concern), and "When I see someone who badly needs help in an emergency, I go to pieces" (personal distress). A confirmatory factor analysis was employed to evaluate the revised three-structure model and rendered a good fit: $\chi^{2}(11)=150.41, p<.001$, comparative fit index $(\mathrm{CFI})=0.97$, standardized root mean squared residual $(\mathrm{SRMR})=0.02$, root mean square error of approximation $($ RMSEA $)=0.08$.

Escape from reality. The 4-item subscale from the Chinese version of Demetrovics et al.'s (2011) Motive for Online Gaming Questionnaire (Wu et al., 2017) was used to tap the gaming motive of escape from reality $(\alpha=.91)$. Participants indicated the frequency of playing online games because of the escape motive on a 5-point scale (ranging from $1=$ almost never/never to $5=$ almost always/always). Sample item includes "I play online games because gaming helps me to forget about daily hassles."

Internet gaming disorder (IGD). The nine diagnostic criteria for IGD listed in the DSM-5 (APA, 2013) were used to evaluate participants' IGD severity. Participants were asked whether each of nine symptoms could describe their own situation in the past 12 months $(0=$ no, $1=$ yes $)$. Its internal consistency (KR-20) was .89. As suggested by Ko et al. (2014), the cut-off point at $4 / 5$ was also used to identify probable IGD cases.

\section{Data analysis}

Since observed indicators of the IGD variable are binary in nature, weighted least squares means and variance adjusted estimator for SEM were employed to test the hypothesized model. All analyses were conducted using the lavaan package in R (Rosseel, 2012). Evaluation of model fit was based on CFI, SRMR, and RMSEA. A model with CFI $>0.90$, SRMR $<0.08$, and RMSEA $<0.08$ is considered as having acceptable fit to the data (Hair, Black, Babin, Anderson, \& Tatham, 2010). To test the indirect effect of the three theorized paths, we conducted a bootstrap analysis in which bias-corrected confidence intervals were constructed by drawing 5,000 random samples with replacement from the full sample.

\section{Ethics}

After participants had read the study purpose and rights of participation and withdrawal and signed the online informed consent for this study, they completed an anonymous online survey using a questionnaire website named WenJuanXing (www.wjx.cn). Since there are no sensitive questions and potential harms to the participants, and it is not practically possible to have all parents informed - many of the participants lived in school dorm and might only go home every several weeks or months - we only obtained school principals' and teachers' approval, which is in line with the practice of the China Education Panel Survey (2014). The research procedures met the requirements of the Declaration of Helsinki. Ethical approval was obtained from the affiliated University of Hong Kong.

\section{RESULTS}

\section{Preliminary analyses}

According to DSM-5 criteria, $13.47 \%$ of the cases were classified as probable IGD. Descriptive statistics are presented in Table 1. The results of bivariate correlations were basically in line with the current hypotheses. For instances, IGD was negatively correlated with perspective taking and empathic concern, $r(3,348)=-.10$ and -.08 , respectively,

Table 1. Summary of means, standard deviations, and intercorrelations for the measures $(N=3,348)$

\begin{tabular}{|c|c|c|c|c|c|c|c|c|}
\hline & & $M(S D)$ & 1 & 2 & 3 & 4 & 5 & 6 \\
\hline 1. & Age & $18.20(2.05)$ & $.12 * * *$ & $.09 * * *$ & $.05 * *$ & -.02 & $-.12 * * *$ & $-.11 * * *$ \\
\hline 2. & Gender $^{\mathrm{a}}$ & - & - & $.13 * * *$ & $.09 * * *$ & .03 & $-.22 * * *$ & $-.20 * * *$ \\
\hline 3. & Perspective taking & $3.55(0.65)$ & & .80 & $.70^{* * *}$ & $.13^{* * *}$ & $-.16^{* * *}$ & $-.10^{* * *}$ \\
\hline 4. & Empathic concern & $3.50(0.66)$ & & & .66 & $.21 * * *$ & $-.10 * * *$ & $-.08 * * *$ \\
\hline 5. & Personal distress & $2.98(0.70)$ & & & & .63 & $.12 * * *$ & $.10^{* * *}$ \\
\hline 6. & Escape from reality & $2.13(0.91)$ & & & & & .91 & $.34 * * *$ \\
\hline 7. & Internet gaming disorder & $1.61(2.49)$ & & & & & & .89 \\
\hline
\end{tabular}

Note. The reliability coefficients are found along the diagonal line. $S D$ : standard deviation.

${ }^{\mathrm{a}}$ Male $=1$, Female $=2$.

${ }^{* *} p<.01 .{ }^{* * *} p<.001$ 
$p<.001$, and positively correlated with personal distress and motive of escape from reality, $r(3,348)=.10$ and .34 , respectively, $p<.001$. Furthermore, motive of escape was correlated with empathic concern negatively and personal distress positively, $r(3,348)=-.10$ and .12 , respectively, $p<.001$. Perspective taking and empathic concern were positively correlated, $r(3,348)=.70, p<.001$.

\section{Hypothesized SEM testing}

SEM results showed that our proposed model fitted the data well, $\chi^{2}(162)=2,066.57, p<.001, \mathrm{CFI}=0.97, \mathrm{SRMR}=$ 0.06 , RMSEA $=0.06$. Standardized factor loadings ranged from 0.51 to 0.92 , with $p<.001$ (Table 2). As shown in Figure 1, IGD was positively predicted by personal distress, $\beta=0.10, p<.001,95 \%$ confidence interval (CI) $[0.05$, $0.15]$, but not by perspective taking, $\beta=-0.30, p=.546$, 95\% CI $[-27.29,0.52]$, and empathic concern, $\beta=0.21$, $p=.675,95 \%$ CI $[-0.44,33.47]$. Furthermore, motive of escape positively predicted IGD, $\beta=0.40, p<.001,95 \% \mathrm{CI}$ $[0.36,0.43]$, while being negatively and positively predicted by empathic concern, $\beta=-0.21,95 \%$ CI $[-0.26,-0.16]$, and personal distress, $\beta=0.21,95 \%$ CIs $[0.14,0.26]$, $p \mathrm{~s}<.001$. Finally, perspective taking positively predicted empathic concern, $\beta=1.02, p<.001,95 \%$ CI $[0.97,1.08]$.

Next, we tested the significance of the three indirect paths: (a) from personal distress, via motive of escape from reality, to IGD; (b) from empathic concern, via motive of escape from reality, to probable IGD; and (c) from perspective taking, via empathic concern, to motive of escape from reality, to IGD. The results of bootstrap analyses showed that the indirect effects of all three hypothesized paths were significant:

Table 2. Unstandardized and standardized factor loadings

\begin{tabular}{llc}
\hline $\begin{array}{l}\text { Parameter } \\
\text { estimates }\end{array}$ & $\begin{array}{c}\text { Unstandardized } \\
\text { loading }(S E)\end{array}$ & $\begin{array}{c}\text { Standardized } \\
\text { loading }\end{array}$ \\
\hline $\mathrm{PT} \rightarrow$ Item P1 & 1.00 & 0.90 \\
$\mathrm{PT} \rightarrow$ Item P2 & $7.39(0.98)^{* * *}$ & 0.78 \\
$\mathrm{PT} \rightarrow$ Item P3 & $6.41(0.84)^{* * *}$ & 0.66 \\
$\mathrm{EC} \rightarrow$ Item C1 & 1.00 & 0.62 \\
$\mathrm{EC} \rightarrow$ Item C2 & $1.25(0.03)^{* * *}$ & 0.75 \\
$\mathrm{PD} \rightarrow$ Item D1 & 1.00 & 0.90 \\
$\mathrm{PD} \rightarrow$ Item D2 & $0.56(0.04)^{* * *}$ & 0.51 \\
$\mathrm{EFR} \rightarrow$ Item E1 & 1.00 & 0.77 \\
$\mathrm{EFR} \rightarrow$ Item E2 & $1.21(0.04)^{* * *}$ & 0.90 \\
$\mathrm{EFR} \rightarrow$ Item E3 & $1.21(0.04)^{* * *}$ & 0.90 \\
$\mathrm{EFR} \rightarrow$ Item E4 & $1.14(0.03)^{* * *}$ & 0.83 \\
IGD $\rightarrow$ Item I1 & 1.00 & 0.83 \\
$\mathrm{IGD} \rightarrow$ Item I2 & $1.00(0.02)^{* * *}$ & 0.83 \\
$\mathrm{IGD} \rightarrow$ Item I3 & $1.04(0.02)^{* * *}$ & 0.87 \\
IGD $\rightarrow$ Item I4 & $1.01(0.02)^{* * *}$ & 0.84 \\
$\mathrm{IGD} \rightarrow$ Item I5 & $1.10(0.02)^{* * *}$ & 0.92 \\
IGD $\rightarrow$ Item I6 & $1.03(0.02)^{* * *}$ & 0.85 \\
IGD $\rightarrow$ Item I7 & $1.09(0.02)^{* * *}$ & 0.90 \\
IGD $\rightarrow$ Item I8 & $0.97(0.02)^{* * *}$ & 0.80 \\
IGD $\rightarrow$ Item I9 & $1.04(0.02)^{* * *}$ & 0.87 \\
\hline
\end{tabular}

Note. SE: standard error; PT: perspective taking; EC: empathic concern; PD: personal distress; EFR: escape from reality; IGD: Internet gaming disorder.

$* * * p<.001$. (a) $\beta=0.08, p<.001$, bias-corrected bootstrap 95\% CI [0.06, 0.11]; (b) $\beta=-0.09, p<.001$, bias-corrected bootstrap $95 \%$ CI $[-0.11,-0.07]$; and (c) $\beta=-0.09, p<.001$, biascorrected bootstrap 95\% CI $[-0.11,-0.07]$. Overall, the predictors explained $20 \%$ of total variance in IGD.

\section{Robustness checks}

We also tested whether our proposed model was reliable across a couple of robustness checks. We first adjusted for age and gender in our SEM analysis. The change of fit indices was minimum, $\mathrm{CFI}=0.95, \quad \mathrm{SRMR}=0.07$, RMSEA $=0.06$, and the significance and direction of all path coefficients did not change. Since the present data set was collected from nine schools, as an additional robustness check, we repeated our SEM analysis with school effect controlled using eight dummy variables of "schools" in each path as predictors. The significance and direction of each coefficient remained the same, and the model fit was nearly identical, CFI $=0.96$, SRMR $=0.06$, RMSEA $=0.06$.

\section{DISCUSSION AND CONCLUSIONS}

Research examining the effects of empathy components on IGD simultaneously is scant. Empirically, this study first adds to a small group of studies that look into the effect of empathy on online gaming addiction. The analyses reported herein provide empirical evidence that perspective taking and empathic concern may have a protective effect, whereas personal distress and gaming motive of escape from reality may have a damaging effect against IGD. In particular, the SEM results showed that personal distress, but not empathic concern or perspective taking, had a direct effect on IGD symptoms. The results also confirmed that there were indirect effects of personal distress and empathic concern on IGD symptoms through gaming motive of escape from reality. The indirect effect of the cognitive component, perspective taking, was also shown.

The overall results provide strong support for our proposed affect-oriented mediation model. Theoretically, adolescents characterized by deficits in self-emotion regulation are probably more prone to regulate their negative emotion, including personal distress in our case, by indulging activities such as online gaming that may make them feel better immediately (Tice, Bratslavsky, \& Baumeister, 2001). Similar to the mechanism for PIU (Mo, Chan, Chan, \& Lau, 2018), online gaming may provide a mean for escaping from negative moods and problems in the reality; thus, it is reasonable that individuals who have high gaming motive of escape from reality are poorly self-regulated (see Cheng et al., 2018), supporting the mediating role of gaming motive of escape from reality. As for the empathic concern pathway, some indirect evidence shows that people who are more likely to experience empathy and sympathy - not personal distress - may sometimes well-regulated (Eisenberg, 2010). It is also well-documented that individuals' ability to regulate their behavior is a major determinant of social outcomes (McKown et al., 2009). Together, these echo our findings that the other-oriented emotion of empathic concern negatively 


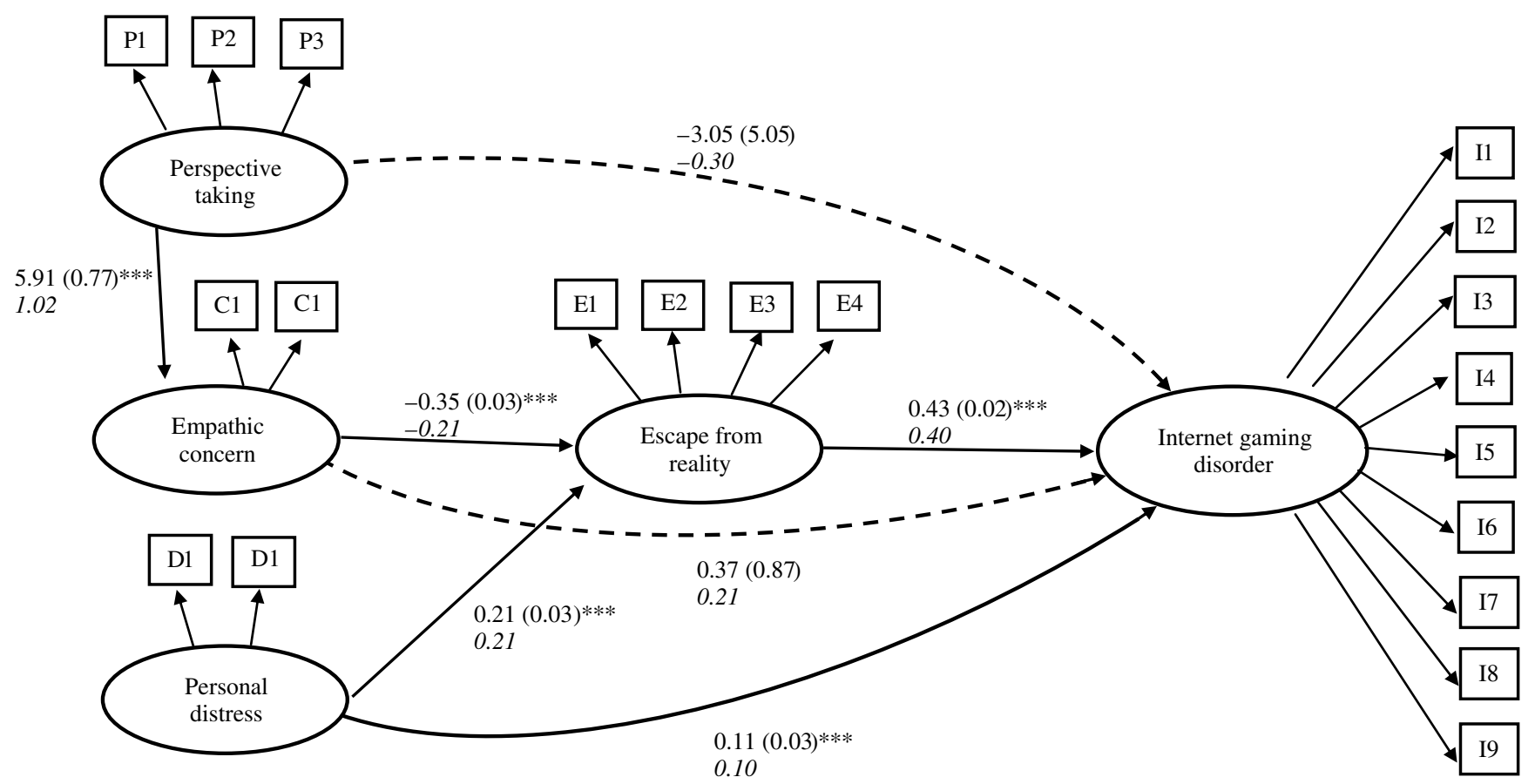

Figure 1. Structural equation model testing the effect of perspective taking, empathic concern, and personal distress on Internet gaming disorder via motive of escape from reality. Note. $N=3,348 . \mathrm{CFI}=0.97$, SRMR $=0.06$, RMSEA $=0.06$. Unstandardized (not italicized) and standardized (italicized) coefficients with standard errors in parentheses are presented. Dashed lines represent a non-significant relationship $(p>.05) . * * * p<.001$

predicts gaming motive of escape from reality, which in turn predicts IGD, as mentioned above.

It is prudent to outline several caveats, which may drive future research directions. First, due to negative total-item correlations, emphatic concern and personal distress were measured by only two items, respectively. Future studies may use other measures of empathy to test the replicability of the findings. Second, we tested the affectoriented pathways and proposed self-regulation as an underlying explanation, but no self-regulation variable is involved in our analyses. Although empathy has been shown to be positively associated with effortful control (e.g., Rothbart et al., 1994), and Seay and Kraut (2007) reported some preliminary results that self-regulation and problematic online gaming are negatively correlated, it is advisable to include the underlying explanatory variable of self-regulation in future research. Furthermore, although this study is correlational in nature, and thus no causality can be derived from the data, our findings are consistent with a number of studies proposing that empathy and/or motive of escape from reality lead/s to pathological video gaming or IGD (e.g., Gentile et al., 2011; Wu et al., 2017). Our work helps build toward the goal that empathy can be protective to IGD. Based on the present research, it will be intriguing to carry out intervention or experimental studies, manipulating different components of empathy (e.g., Konrath, 2017; Malti, Chaparro, Zuffianò, \& Colasante, 2016) and testing its influence on online gaming and IGD. Finally, this study entirely targeted on the higher vulnerable group of adolescents to IGD; it is equally important to examine our proposed model in different age groups (e.g., Wu et al., 2018). Psychological constructs are always influenced by culture, in which IGD is not an exception (Cheng et al., 2018); future research studying cultural variations will enrich the model and provide insights into the specific social and cultural conditions under, which it may work.

To conclude, empathy is a negative correlate of IGD, and potential motivational mediators, including escape from reality, should be noted. Our findings provide empirical support to the salient role of affects (i.e., personal distress and empathic concern) in the two pathways of IGD. Given that IGD has imposed a serious public health threat (e.g., 13.47\% in our sample), our investigation is timely and shows that empathy is a new, yet potentially important variable, which may help mitigate the condition of online gaming addiction and thus its adverse effects to the society. We hope that this study - in addition to future work examining the causal effect of empathy on gaming addiction - helps provide conceptual and empirical basis for developing personalized, adaptive interventions for IGD.

Funding sources: This research was supported by the CRF, Research Grants Council of the Hong Kong Special Administrative Region, China (C5010-15G).

Authors' contribution: Dr. BPHH was responsible for the study concept and design, participated in the data collection, conducted the data analysis, interpreted the findings, and was involved in the manuscript writing and revision. Prof. AMSW was responsible for the study concept and data interpretation and was involved in the manuscript writing and revision. Prof. NP was the principal investigator of the project. She was responsible for obtaining the funding and participated in the study design, data collection, and 
manuscript revision. All authors had full access to all data in the study and take responsibility for the integrity of the data and the accuracy of the data analysis. All authors contributed to and approved the final version of the manuscript.

Conflict of interest: All authors declare that they have no conflicts of interest.

Acknowledgements: The authors like to thank Gao Hang, Hou Liqi, Lin Lin, Song Xinmiao, Vladislav Xu, and Li De Pin for their support with data collection. They would like to show their deep appreciation to the numerous school administrators, teachers, and pupils for participating in this project, especially those from Anqing Vocational \& Technical College, E-Business Logistics and High Speed Train Attendant Department, Inner Mongolia Linhe Number 1 Vocational School, Hang Jin Hou Qi Vocational Training Center, Inner Mongolia, Inner Mongolia Huancheng Vocational Technical School, Lanzhou Modern Vocational College, Shaanxi Institute of Technology, and Xiaogan Vocational School, Hubei Province.

\section{REFERENCES}

Allison, S. E., von Wahlde, L., Shockley, T., \& Gabbard, G. O. (2006). The development of the self in the era of the Internet and role-playing fantasy games. American Journal of Psychiatry, 163(3), 381-385. doi:10.1176/appi.ajp.163.3.381

American Psychiatric Association [APA]. (2013). Diagnostic and statistical manual of mental disorders (5th ed.). Washington, DC: American Psychiatric Association.

Baron-Cohen, S., \& Wheelwright, S. (2004). The empathy quotient: An investigation of adults with Asperger syndrome or high functioning autism, and normal sex differences. Journal of Autism and Developmental Disorders, 34(2), 163-175. doi:10.1023/B:JADD.0000022607.19833.00

Batson, C. D., Early, S., \& Salvarani, G. (1997). Perspective taking: Imagining how another feels versus imagining how you would feel. Personality and Social Psychology Bulletin, 23(7), 751-758. doi:10.1177/0146167297237008

Batson, D. (2018). Empathy, altruism, and helping: Conceptual distinctions, empirical relations. In $\mathrm{N}$. Roughley \& $\mathrm{T}$. Schramme (Eds.), Forms offellow feeling: Empathy, sympathy, concern and moral agency (pp. 59-77). Cambridge, UK: Cambridge University Press.

Berry, D. R., Cairo, A. H., Goodman, R. J., Quaglia, J. T., Green, J. D., \& Brown, K. W. (2018). Mindfulness increases prosocial responses toward ostracized strangers through empathic concern. Journal of Experimental Psychology: General, 147(1), 93-112. doi:10.1037/xge0000392

Busby, D. M., \& Gardner, B. C. (2008). How do I analyze thee? Let me count the ways: Considering empathy in couple relationships using self and partner ratings. Family Process, 47(2), 229-242. doi:10.1111/j.1545-5300.2008.00250.x

Caplan, S. E. (2002). Problematic Internet use and psychosocial well-being: Development of a theory-based cognitivebehavioral measurement instrument. Computers in Human Behavior, 18(5), 553-575. doi:10.1016/S0747-5632(02) 00004-3
Carlo, G., Mestre, M. V., McGinley, M. M., Samper, P., Tur, A., \& Sandman, D. (2012). The interplay of emotional instability, empathy, and coping on prosocial and aggressive behaviors. Personality and Individual Differences, 53(5), 675-680. doi:10.1016/j.paid.2012.05.022

Che, D., Hu, J., Zhen, S., Yu, C., Li, B., Xi, C., \& Zhang, W. (2017). Dimensions of emotional intelligence and online gaming addiction in adolescence: The indirect effects of two facets of perceived stress. Frontiers in Psychology, 8, 1-8. doi:10. 3389/fpsyg.2017.01206

Cheng, C., Cheung, M. W.-L., \& Wang, H. (2018). Multinational comparison of Internet gaming disorder and psychosocial problems versus well-being: Meta-analysis of 20 countries. Computers in Human Behavior, 88, 153-167. doi:10.1016/j. chb.2018.06.033

China Education Panel Survey. (2014). Wave 1 baseline manual [in Chinese]. Retrieved from https://ceps.ruc.edu.cn/assets/ admin/org/ueditor/php/upload/20150415/14290791249394.pdf

China Internet Network Information Center [CINIC]. (2016). 2014-2015 China mobile gaming users research report [in Chinese]. Retrieved from http://www.cnnic.cn/hlwfzyj/ hlwxzbg/wybg/201601/P020160105430794926978.pdf

China Internet Network Information Center [CINIC]. (2018). Statistical report on Internet development in China (January 2018) [in Chinese]. Retrieved from http://www.cac.gov.cn/ 2018-01/31/c_1122347026.htm

Christov-Moore, L., Simpson, E. A., Coudé, G., Grigaityte, K., Iacoboni, M., \& Ferrari, P. F. (2014). Empathy: Gender effects in brain and behavior. Neuroscience and Biobehavioral Reviews, 46, 604-627. doi:10.1016/j.neubiorev.2014.09.001

Collins, E., \& Freeman, J. (2013). Do problematic and non-problematic video game players differ in extraversion, trait empathy, social capital and prosocial tendencies? Computers in Human Behavior, 29(5), 1933-1940. doi:10.1016/j.chb.2013.03.002

Davis, M. H. (1983). Measuring individual differences in empathy: Evidence for a multidimensional approach. Journal of Personality and Social Psychology, 44(1), 113-126. doi:10.1037/ 0022-3514.44.1.113

Davis, M. H. (1994). Empathy: A social psychological approach. Boulder, CO: Westview Press.

Demetrovics, Z., Urbán, R., Nagygyörgy, K., Farkas, J., Zilahy, D., Mervó, B., Reindl, A., Ágoston, C., Kertész, A., \& Harmath, E. (2011). Why do you play? The development of the Motives for Online Gaming Questionnaire (MOGQ). Behavior Research Methods, 43(3), 814-825. doi:10.3758/s13428-0110091-y

De Wied, M., Branje, S. J., \& Meeus, W. H. (2007). Empathy and conflict resolution in friendship relations among adolescents. Aggressive Behavior, 33(1), 48-55. doi:10.1002/ab.20166

Eisenberg, N. (2010). Empathy-related responding: Links with self-regulation, moral judgment, and moral behavior. In M. Mikulincer \& P. R. Shaver (Eds.), Prosocial motives, emotions, and behavior: The better angels of our nature (pp. 129-148). Washington, DC: American Psychological Association.

Eisenberg, N., \& Miller, P. A. (1987). The relation of empathy to prosocial and related behaviors. Psychological Bulletin, 101(1), 91-119. doi:10.1037/0033-2909.101.1.91

Eisenberg, N., \& Okun, M. A. (1996). The relations of dispositional regulation and emotionality to elders' empathy-related responding and affect while volunteering. Journal of Personality, 64(1), 157-183. doi:10.1111/j.1467-6494.1996.tb00818.x 
Eisenberg, N., Wentzel, N. M., \& Harris, J. D. (1998). The role of emotionality and regulation in empathy-related responding. School Psychology Review, 27, 506-521. Retrieved from http://psycnet.apa.org/record/1999-00154-004

Engelberg, E., \& Sjöberg, L. (2004). Internet use, social skills, and adjustment. CyberPsychology \& Behavior, 7(1), 41-47. doi:10.1089/109493104322820101

Fineberg, N., Demetrovics, Z., Stein, D., Ioannidis, K., Potenza, M., Grünblatt, E., Brand, M., Billieux, J., Carmi, L., King, D. L., Grant, J. E., Yücel, M., Dell'Osso, B., Rumpf, H. J., Hall, N., Hollander, E., Goudriaan, A., Menchon, J., Zohar, J., Burkauskas, J., Martinotti, G., Van Ameringen, M., Corazza, O., Pallanti, S., COST Action Network, \& Chamberlain, S. (2018). Manifesto for a European research network into problematic usage of the Internet. European Neuropsychopharmacology, 28(11), 1232-1246. doi:10.1016/j.euroneuro.2018. 08.004

Funk, J., Fox, C., Chan, M., \& Curtiss, K. (2008). The development of the Children's Empathic Attitudes Questionnaire using classical and Rasch analyses. Journal of Applied Developmental Psychology, 29(3), 187-196. doi:10.1016/j.appdev.2008. 02.005

Gentile, D. A., Choo, H., Liau, A., Sim, T., Li, D., Fung, D., \& Khoo, A. (2011). Pathological video game use among youths: A two-year longitudinal study. Paediatrics, 127(2), e319e329. doi:10.1542/peds.2010-1353

Hair, J. F., Black, W. C., Babin, B. J., Anderson, R. E., \& Tatham, R. L. (2010). Multivariate data analysis (7th ed.). Upper Saddle River, NJ: Prentice-Hall.

Jiao, C., Wang, T., Peng, X., \& Cui, F. (2017). Impaired empathy processing in individuals with Internet addiction disorder: An event-related potential study. Frontiers in Human Neuroscience, 11, 498. doi:10.3389/fnhum.2017.00498

King, D. L., Delfabbro, P. H., Potenza, M. N., Demetrovics, Z., Billieux, J., \& Brand, M. (2018). Internet gaming disorder should qualify as a mental disorder. Australian and New Zealand Journal of Psychiatry, 52(7), 615-617. doi:10. $1177 / 0004867418771189$

Király, O., Urbán, R., Griffiths, M. D., Ágoston, C., Nagygyörgy, K., Kökönyei, G., \& Demetrovics, Z. (2015). The mediating effect of gaming motivation between psychiatric symptoms and problematic online gaming: An online survey. Journal of Medical Internet Research, 17(4), e88. doi:10.2196/jmir.3515

Ko, C. H., Yen, J. Y., Chen, S. H., Wang, P. W., Chen, C. S., \& Yen, C. F. (2014). Evaluation of the diagnostic criteria of Internet gaming disorder in the DSM-5 among young adults in Taiwan. Journal of Psychiatric Research, 53, 103-110. doi:10.1016/j.jpsychires.2014.02.008

Konrath, S. (2017, March 14). Empathy: There's an app for that! Retrieved from https://www.psychologytoday.com/intl/blog/ the-empathy-gap/201703/empathy-there-s-app

Kuss, D. J. (2013). Internet gaming addiction: Current perspectives. Psychology Research and Behavior Management, 6, 125-137. doi:10.2147/PRBM.S39476

Lachmann, B., Sindermann, C., Sariyska, R. Y., Luo, R., Melchers, M. C., Becker, B., Cooper, A. J., \& Montag, C. (2018). The role of empathy and life satisfaction in Internet and smartphone use disorder. Frontiers in Psychology, 9, 1-11. doi:10.3389/ fpsyg.2018.00398

LaRose, R., Lin, C. A., \& Eastin, M. S. (2003). Unregulated Internet usage: Addiction, habit, or deficient self-regulation?
Media Psychology, 5(3), 225-253. doi:10.1207/S1532785 XMEP0503_01

Lemmens, J. S., Valkenburg, P. M., \& Peter, J. (2011). Psychosocial causes and consequences of pathological gaming. Computers in Human Behavior, 27(1), 144-152. doi:10.1016/j. chb.2010.07.015

Liau, A. K., Choo, H., Li, D., Gentile, D. A., Sim, T., \& Khoo, A. (2015). Pathological video-gaming among youth: A prospective study examining dynamic protective factors. Addiction Research \& Theory, 23(4), 301-308. doi:10.3109/16066359. 2014.987759

Liau, A. K., Tan, T. K., Li, D., \& Khoo, A. (2012). Factorial invariance of the Personal Strengths Inventory-2 for children and adolescents across school level and gender. European Journal of Psychology of Education, 27(4), 451-465. doi:10.1007/s10212-011-0088-z

Lo, S., Wang, C., \& Fang, W. (2005). Physical interpersonal relationships and social anxiety among online game players. CyberPsychology \& Behavior, 8(1), 15-20. doi:10.1089/cpb. 2005.8.15

Malti, T., Chaparro, M. P., Zuffianò, A., \& Colasante, T. (2016). School-based interventions to promote empathy-related responding in children and adolescents: A developmental analysis. Journal of Clinical Child \& Adolescent Psychology, 45(6), 718-731. doi:10.1080/15374416.2015.1121822

Maniaci, M. R., \& Rogge, R. D. (2014). Caring about carelessness: Participant inattention and its effects on research. Journal of Research in Personality, 48, 61-83. doi:10.1016/j.jrp.2013. 09.008

McKown, C., Gumbiner, L. M., Russo, N. M., \& Lipton, M. (2009). Social-emotional learning skill, self-regulation, and social competence in typically developing and clinic-referred children. Journal of Clinical Child \& Adolescent Psychology, 38(6), 858-871. doi:10.1080/15374410903258934

Meade, A. W., \& Craig, S. B. (2012). Identifying careless responses in survey data. Psychological Methods, 17(3), 437-455. doi:10.1037/a0028085

Melchers, M., Li, M., Chen, Y., Zhang, W., \& Montag, C. (2015). Low empathy is associated with problematic use of the Internet: Empirical evidence from China and Germany. Asian Journal of Psychiatry, 17, 56-60. doi:10.1016/j.ajp. 2015.06.019

Mo, P. K. H., Chan, V. W. Y., Chan, S. W., \& Lau, J. T. F. (2018). The role of social support on emotion dysregulation and Internet addiction among Chinese adolescents: A structural equation model. Addictive Behaviors, 82, 86-93. doi:10.1016/ j.addbeh.2018.01.027

Penner, L. A. (2002). Dispositional and organizational influences on sustained volunteerism: An interactionist perspective. Journal of Social Issues, 58(3), 447-467. doi:10.1111/15404560.00270

Posner, M. I., \& Rothbart, M. K. (2000). Developing mechanisms of self regulation. Development and Psychopathology, 12(3), 427-441. doi:10.1017/S0954579400003096

Rehbein, F., Kleimann, M., \& Mößle, T. (2010). Prevalence and risk factors of video game dependency in adolescence: Results of a German nationwide survey. Cyberpsychology, Behavior, and Social Networking, 13(3), 269-277. doi:10.1089/cyber. 2009.0227

Riggio, R. E., \& Taylor, S. J. (2000). Personality and communication skills as predictors of hospice nurse performance. Journal 
of Business and Psychology, 15(2), 351-359. doi:10.1023/ A:1007832320795

Rosseel, Y. (2012). lavaan : An R package for structural equation modeling. Journal of Statistical Software, 48(2), 1-36. doi:10.18637/jss.v048.i02

Rothbart, M. K., Ahadi, S. A., \& Hershey, K. L. (1994). Temperament and social behavior in childhood. Merrill-Palmer Quarterly, 40, 21-39. doi:10.1037/0021-843X.103.1.55

Rumpf, H.-J., Achab, S., Billieux, J., Bowden-Jones, H., Carragher, N., Demetrovics, Z., Higuchi, S., King, D. L., Mann, K., Potenza, M., Saunders, J. B., Abbott, M., Ambekar, A., Aricak, O. T., Assanangkornchai, S., Bahar, N., Borges, G., Brand, M., Chan, E. M., Chung, T., Derevensky, J., Kashef, A. E., Farrell, M., Fineberg, N. A., Gandin, C., Gentile, D. A., Griffiths, M. D., Goudriaan, A. E., Grall-Bronnec, M., Hao, W., Hodgins, D. C., Ip, P., Király, O., Lee, H. K., Kuss, D., Lemmens, J. S., Long, J., Lopez-Fernandez, O., Mihara, S., Petry, N. M., Pontes, H. M., Rahimi-Movaghar, A., Rehbein, F., Rehm, J., Scafato, E., Sharma, M., Spritzer, D., Stein, D. J., Tam, P., Weinstein, A., Wittchen, H. U., Wölfling, K., Zullino, D., \& Poznyak, V. (2018). Including gaming disorder in the ICD-11: The need to do so from a clinical and public health perspective. Journal of Behavioral Addictions, 7(3), 556-561. doi:10.1556/2006.7.2018.59

Seay, A. F., \& Kraut, R. E. (2007). Project massive: Self-regulation and problematic use of online gaming. Paper presented at the CHI 2007, San Jose, CA, USA.

Tejeiro, R. A., Gómez-Vallecillo, J. L., Pelegrina, M., Wallace, A., \& Emberley, E. (2012). Risk factors associated with the abuse of video games in adolescents. Psychology, 3(4), 310-314. doi:10.4236/psych.2012.34044

Tice, D. M., Bratslavsky, E., \& Baumeister, R. F. (2001). Emotional distress regulation takes precedence over impulse control: If you feel bad, do it! Journal of Personality and Social Psychology, 80(1), 53-67. doi:10.1037/0022-3514.80.1.53 van Ingen, E., \& Matzat, U. (2018). Inequality in mobilizing online help after a negative life event: The role of education, digital skills, and capital-enhancing Internet use. Information Coтmunication and Society, 21(4), 481-498. doi:10.1080/1369118X. 2017.1293708

Wang, T., Ge, Y., Zhang, J., Liu, J., \& Luo, W. (2014). The capacity for pain empathy among urban Internet-addicted leftbehind children in China: An event-related potential study. Computers in Human Behavior, 33, 56-62. doi:10.1016/j.chb. 2013.12.020

Whang, L. S. M., Lee, S., \& Chang, G. (2003). Internet over-users' psychological profiles: A behavior sampling analysis on Internet addiction. CyberPsychology \& Behavior, 6(2), 143-150. doi:10.1089/109493103321640338

World Health Organization [WHO]. (2018). ICD-11 for mortality and morbidity statistics. 6C51 gaming disorder. Retrieved from https://icd.who.int/browse11/1-m/en\#/http://id.who.int/icd/ entity/1448597234

Wu, A. M. S., Chen, J. H., Tong, K.-K., Yu, S., \& Lau, J. T. F. (2018). Prevalence and associated factors of Internet gaming disorder among community dwelling adults in Macao, China. Journal of Behavioral Addictions, 7(1), 62-69. doi:10.1556/ 2006.7.2018.12

Wu, A. M. S., Lai, M. H. C., Yu, S., Lau, J. T. F., \& Lei, M. (2017). Motives for Online Gaming Questionnaire: Its psychometric properties and correlation with Internet gaming disorder symptoms among Chinese people. Journal of Behavioral Addictions, 6(1), 11-20. doi:10.1556/2006.6.2017.007

Zhang, Y., Zhang, W., Wu, Q, Yu, C., Chen, M., \& Lin, S. (2016). Mobile phone gaming addiction and empathy among medical undergraduates: The mediating role of depression [in Chinese]. China Journal of Health Psychology, 4, 570-573. Retrieved from http://caod.oriprobe.com/articles/47941153/ Mobile_Phone_Gaming_Addiction_and_Empathy_among Medical_Undergraduates.htm 